\title{
EXPERIMENTAL DEVICE FOR DETERMINING DEVIATIONS IN THE THORACOLUMBAR PART OF THE HUMAN BACK
}

\section{Ing. František Horvát, doc. Ing. Branislav Hučko, PhD., Ing. Michal Čekan, PhD., Ing. Lukáš Šoltés}

Department of Applied Mechanics and Mechatronics, Faculty of Mechanical Engineering STU, Námestie slobody 17,812 31 Bratislava, Slovak Republic, frantisek.horvat@stuba.sk, branislav.hucko@stuba.sk,michal.cekan@stuba.sk,lukas.soltes@stuba.sk

Keywords: spine, spinal diseases, optical measuring device, MATLAB, measurement accuracy

Abstract: The article deals with the design and construction of an experimental device for measuring deviations in the thoracolumbar area of the human back. The article describes the devices construction, processing of measured data in the program MATLAB and the interpretation of the data in the form of a 3-D model. From this experimental device we would like to contribute to existing measuring devices with similar accuracy albeit in a more compact and user friendly package, which doesn't require a high degree of qualification to operate.

\section{INTRODUCTION}

Spinal diseases, which result in the deformation of the spine, are currently amongst the most common diseases as the human develops. The early diagnosis of these diseases is crucial in stopping their further progression, and even reversing their effect. For this purpose, a wide range of diagnostic devices are used. With our experiment we wish to introduce a more compact, less invasive device capable of comparable accuracy to already existing devices, and at the same time, doesn't require a high degree of qualification to operate.

Before actually designing and realizing the experimental device it is important to understand the physiological, anatomical, and orthopaedic aspects of the human body together with radio diagnostics. In terms of human anatomy it is important to understand the planes ( $p$.)of the human body. These planes are divided into the following:

- medial p. - the vertical plane which divides the human body into a mirror image of each half

- frontal p. - the vertical plane which is parallel with the forehead (perpendicular to the medial)

- transverse p. - the horizontal plane which is perpendicular to the medial and frontal planes. 
To visualize the above mentioned planes on the human body we must consider a person's so called orthostatic position. This position is almost always defined as standing upright with the upper limbs freely hanging along the body with the palms facing forward. Figure 1 shows the human body planes on an orthostatic human posture. [1]

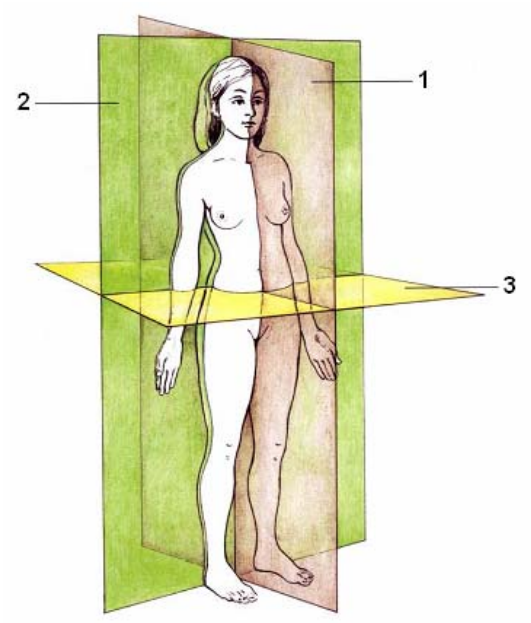

Figure 1: Human body planes: 1 - medial p. 2 - frontal p. 3 -transverse p. [1]

The scientific topic of orthopaedics deals with diseases which effect the human spine as well as diseases which effect human mobility. Diseases affecting the human back often manifests itself in the sideways deformation of the spinal column. In general we can divide these diseases into:

- $\quad$ birth or developmental defects, which occur most commonly in the cervical area of the spinal column as well as between the lumbar and sacral parts (lumbar-sacral transition). These types of deceases usually occur at the formation of the first segments of the vertebrae, that is in the third week after conception. [2]

- $\quad$ developed disorders and diseases, are most commonly diagnosed by doctors in adolescent patients. The usual causes are improper posture, obesity, atrophy of the stomach or back muscles. [2]

Roentgen (X-ray) is one of the basic elements in determining a medical history of the person - patient together with determining their current situation. These two elements form the basis for the objective examination and adequate diagnosis of the spinal column. For this purpose a wide range of devices are used such as: roentgen (RTG), computed tomography (CT), magnetic resonance imaging (MRI), and ultrasonography (USG). [3]

\section{EXPERIMENT}

The experimental device (ED) works on the principle of optical surface scanning. The reflective properties of the scanned surface $(E)$ causes changes in the intensity of light emitted 
( $L E, L R)$. The results of these changes in emitted light is an image of the scanned surface in TIFF format $(D A)$. Following this, the image is then processed into 3-D through the (MATLAB) application. The principles of the method are described in the scheme on figure 2. [4], [5], [6]

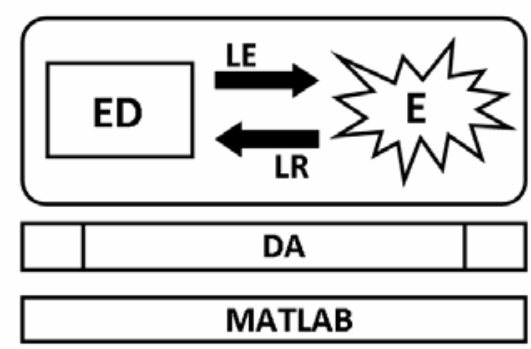

Figure 2: Principle schematic of the device, where ED - experimental device, E - scanned surface, $L E$ - light emitted, LR - light reflected, DA - data acquisition, MATLAB - processing environment

The block diagram of the device can be seen in figure 3 . We can divide these blocks into four groups:

1.) frame of the device, which for our purposes, is constructed of MDF board.

2.) the scanning head together with the light energy blocks (LB1, LB2). This assembly functions by moving parallel to the scanned object.

3.) motion system, which consists of a step motor (M), timing belt (TB) and guide rod (GR). The purpose of this component is to ensure the smooth motion of the scanning head.

4.) controller $(C)$ and communication interface (CI) together with the power supply (PS).

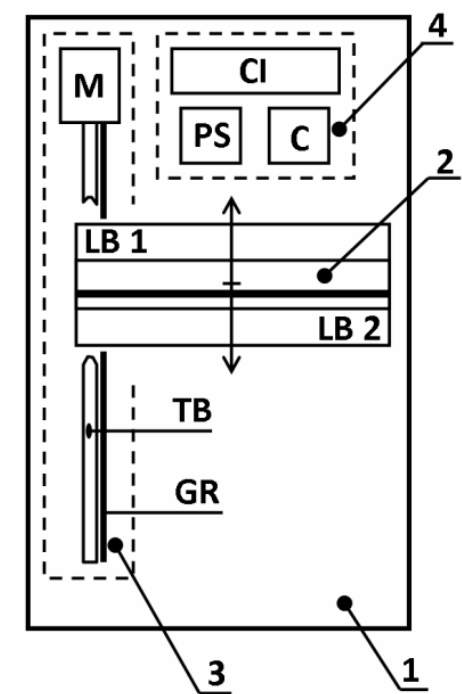

Figure 3: Block diagram of the device, where 1) is the frame of the device, 2) is the scanning head together with LB1 \& LB2 - light energy blocks, 3) the motion system with M - step motor, TB- 
timing belt, and GR-guide rod, and 4) the communication and control block with $C$-controller, CI - communications interface, PS - power supply

The transformation of the scanned image into three-dimensional form is performed on the basis of the intensity of the scanned points. The distance is determined as the difference between the lowest and highest points of the measured object from the same base, which is expressed in formula (1). The schematic representation for determining the reference distance can be seen in figure 4. [4]

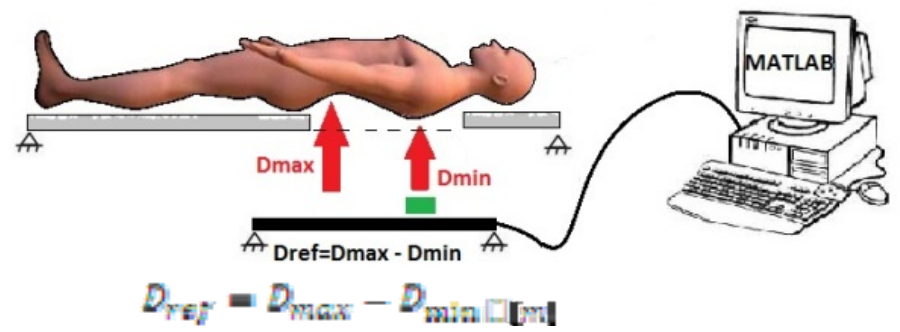

Figure 4: Determining the reference distance [6]

Processing of the measured values were realized in the program MATLAB. For this purpose the application „Analyza chrbtice“ was created. This application not only allows for the transformation of the scanned image but also the ability to use filters such as: average, disk, Gaussian, Laplace and others. The filter is possible to use either in a predefined regime or with the possibility to choose the parameters. Other than the 3-D model of the spine it is possible to create 3-D sections of the scanned image within the transverse plane and graphically display them. In figure 5 the ,Analyza chrbtice“ application can be seen. [5], [6]

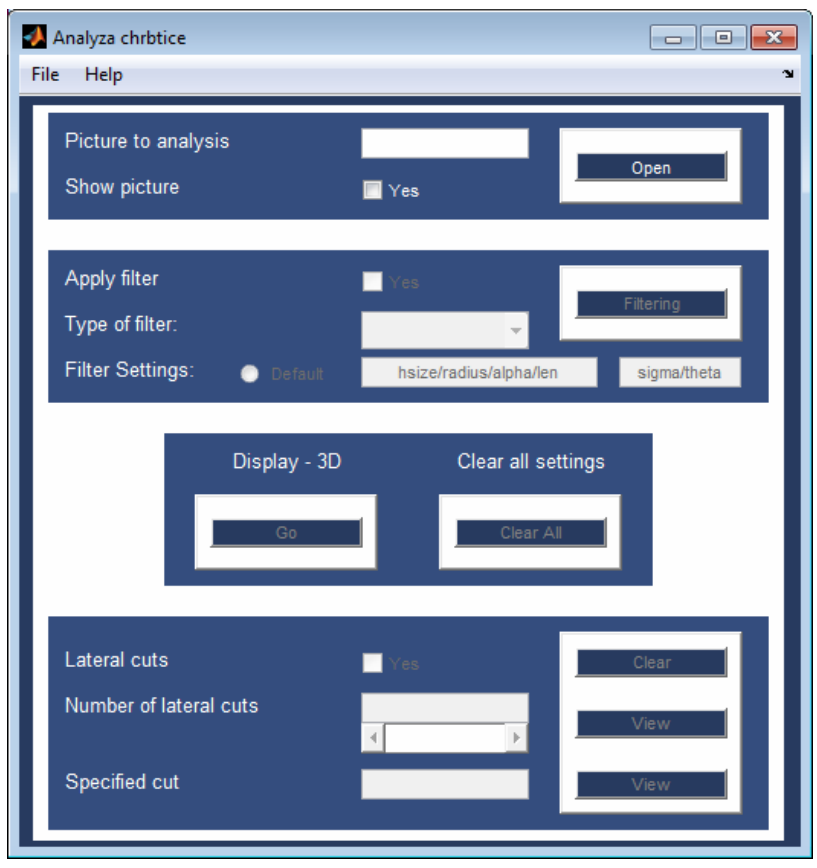


Figure 5: „Analyza chrbtice“ Application [6]

The functionality of the device was verified on a polystyrene model with synthetic of the human back with a synthetic coating, as well as directly on the back of the human body. The difference between the lowest and highest points on the model, which according to equation (1) represent the reference distance $D_{\text {reff }}$, was $0,11[\mathrm{~m}]$. For clarity, the resulting 3-D model is colour coded. Color coding allows for the very simple and practical determination of distance values at any point of the 3-D model. Dark blue regions of the color spectrum correspond to values equal to $0[\mathbf{m}]$, whereas dark red regions correspond to the values of $D_{\text {ref }}$. The scanned model and its 3-D representation processed by the application ,Analyza Chrptice“ can be seen in Figure 6.
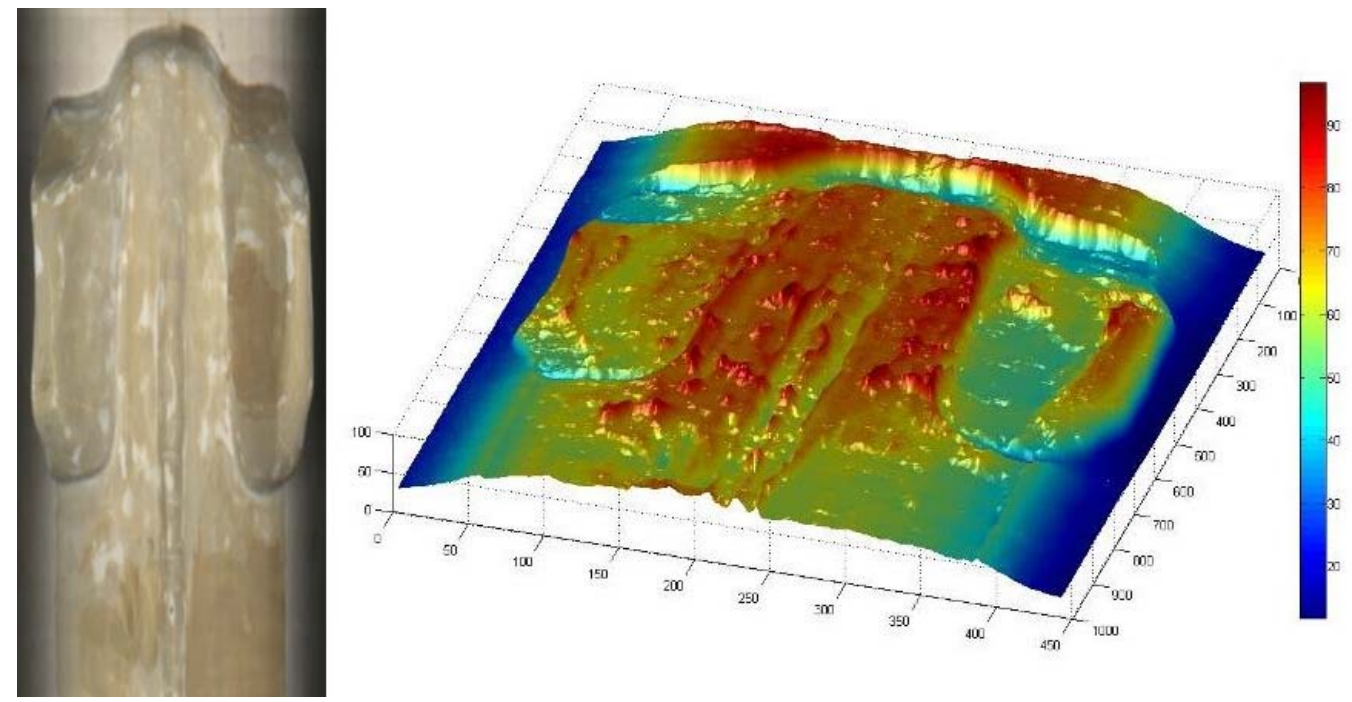

Figure 6: Scan of polystyrene model [6]
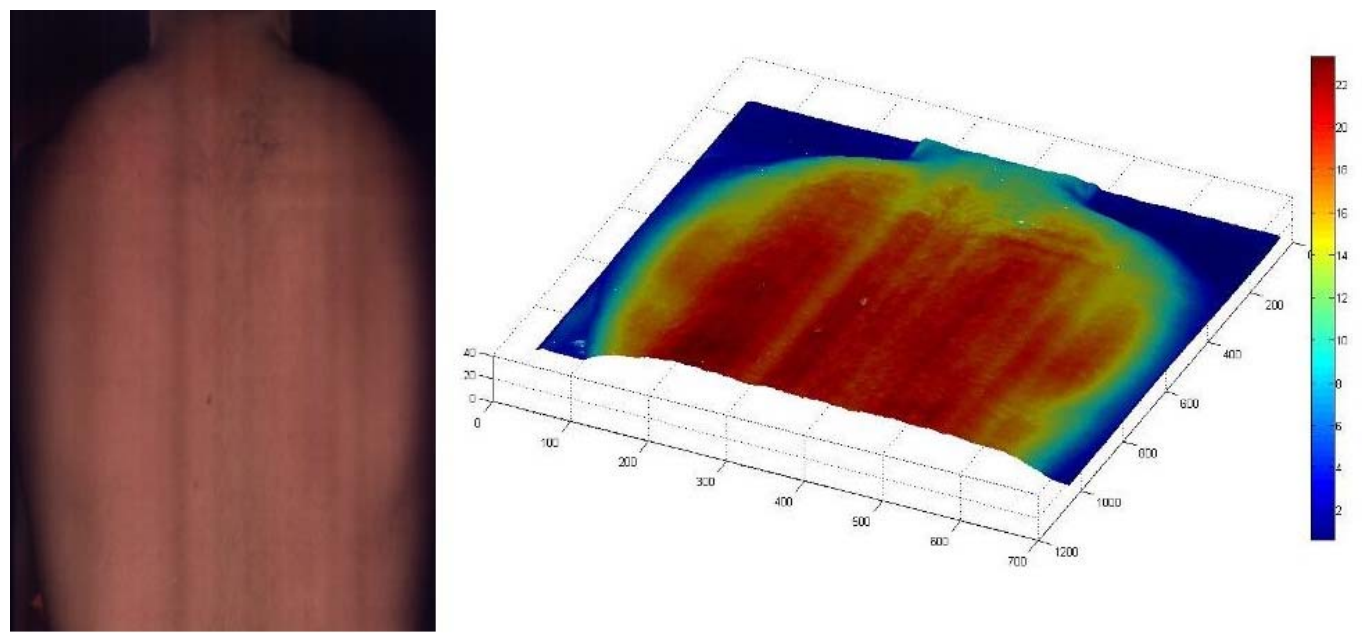

Figure 7: Human back scan [6] 
In the case of measurements directly on the human body, whose image and processed 3-D model can be seen in figure 7, $D_{r e f}=0,025$ [m]. In this case the interpretation of the colour spectrum are the same as in the previous case. The visible deformation of the spinal column is due to the patient laying on their back on top of the measuring device.

\section{EVALUATING THE RESULTS}

The scans of the polystyrene model and the human back itself where performed under the same conditions and device parameters. The results of measurements on the polystyrene model (figure 6) do not correspond with reality, but show the non-homogeneity of the surface of the model itself. This non-homogeneity results in the significant local changes in light intensity. These changes manifested themselves as pyramid-like surfaces on the 3-D model. From the measurements performed directly on the human back (figure 7) we established an accuracy

between In this case, we can say that the 3-D model corresponds well with reality. The range of accuracy when measuring directly on the human back is affected by the amount of bodily hair, oil content on the skin, and any acne present. Any bodily hair affecting our measurements can be shaven, and oily skin as well as acne can be removed by specific cosmetic products.

\section{CONCLUSION}

For the purposes of the experiment, it was enough to have the patient lay on the experimental device. Based on the results obtained through measurements we can conclude that the experimental device was sufficiently accurate in diagnosing any spinal related problems in the thoracolumbar area of the spine. For a more realistic representation of the human back it would be advantageous to modify the device such, that the scan can be performed while the patient is in the orthostatic position. Regardless, the device proves to be highly mobile with an approximate weight of only 10 [kg]. The program developed was specifically designed to be very user friendly, as well as capable to be executed on any mobile laptop or PC.

\section{REFERENCES}

[1] Čihák, R.: Anatomie 1. Praha: Grada, 2002.

[2] Huraj, E.; Červeňanský, J.: Ortopédia. Bratislava: UK v Bratislave, 1975.

[3] Chudáček, Z.: Radiodiagnostika. Martin: Osveta, 1993.

[4] International Image Sensor Society.: IISS . [Online] http://www.imagesensors.org/.

[5] MathWorks, Inc.: MATLAB - The Language of Technical Computing. [Online] http://www.mathworks.com/products/matlab/.

[6] Horvát, F.: Zariadenie pre skenovanie chrbta. Diploma thesis STU BA 2011. 